\title{
Reduced Coxsackie Antibody Titres in Type 1 (Insulin-Dependent) Diabetic Patients Presenting During an Outbreak of Coxsackie B3 and B4 Infection
}

\author{
J.P.Palmer ${ }^{1}$, M. K.Cooney ${ }^{2}$, R. H. Ward*, J.A.Hansen ${ }^{1,3}$, J. B. Brodsky ${ }^{1}$, \\ C. G. Ray**, J. R. Crossley ${ }^{4}$, C. M. Asplin ${ }^{1}$, and R. H. Williams ${ }^{1}$
}

Diabetes Research Center, Departments of ${ }^{1}$ Medicine, ${ }^{2}$ Epidemiology and Pathobiology, University of Washington, Seattle, Washington, the ${ }^{3}$ Puget Sound Blood Center and the ${ }^{4}$ Department of Pediatrics, University of Auckland, Auckland, New Zealand

\begin{abstract}
Summary. The potential role of antecedent viral infection in the pathogenesis of Type 1 (insulin-dependent) diabetes was investigated by measuring antibody titres to several viruses in serum obtained at the time of diagnosis of diabetes. An outbreak of Coxsackie B 4 infection followed by a wave of Coxsackie B3 and B 5 infections occurred in Seattle during the time viral serology was obtained in the diabetic patients. Antibody titres to Cocksackie B 5 and Influenza A and B viruses were comparable in diabetics and matched control subjects, but antibody titres to Cocksackie B3 and B 4 were lower in the diabetics and a low antibody titre to Coxsackie B3/B 4 was associated with a significantly increased relative risk of diabetes.
\end{abstract}

Key words: Type 1 diabetes, virus, Coxsackie B 4, antibody titres.

Coxsackie B viral infections have been implicated as a possible important cause of Type 1 (insulin-dependent) diabetes [1-5]. To investigate the potential relationship of antecedent Coxsackie B viral infection and the onset of Type 1 diabetes, we analyzed antibody titres to Coxsackie B3, B 4, and B 5 in serum obtained from Type 1 diabetic patients at the time of diagnosis, and from matched non-diabetic subjects. In addition, we monitored the relative prevalence of Coxsackie B viral infections in the greater Seattle Area during the period viral serology was obtained in the diabetics and observed an outbreak of Coxsackie B 4 infections followed by a wave of Coxsackie B3 and $\mathrm{B} 5$.

* Present address: Dept. of Medical Genetics, University of British Columbia, Vancouver, B. C., Canada

** Present address: Dept. of Pathology and Pediatrics, University of Arizona, Tucson, Arizona, USA

\section{Methods}

\section{Subjects}

Two groups of subjects were evaluated. Thirty-three newly diagnosed Type 1 diabetic patients, who presented from March 1976 to June 1978 in ketoacidosis or with a short duration of classic diabetic symptoms, participated in the study. Serum was obtained within 1 week of diagnosis (mean $=3.3$ days) in 30 of the patients, within 2 weeks in one and within 4 weeks in two patients. Two hundred and fifty families, totalling over 800 non-diabetic individuals, who participated in a viral surveillance project from October 1975 to May 1979 , were also studied. Blood was drawn from these individuals every 4 months and combined nose and throat swabs were obtained for viral cultures every 2 weeks and at the time of illness.

\section{Procedures}

Coxsackie B 3, B 4, B 5 and Influenza A and B antibody titres were determined by standard neutralizing and complement fixing techniques, the titre being expressed as the reciprocal of the highest dilution showing the complete reaction [6]. Sera with known concentrations of antibody were included with each assay and their titres did not vary more than twofold between and within the assays. Coxsackie viruses from the nose/throat cultures were isolated on primary monkey kidney cells [6]. Islet cell cytoplasmic antibodies were measured by indirect immunofluorescence [6]. Typing for HLA-A and B antigens was performed using the standard NIH two-stage microcytotoxicity assay [7].

\section{Data Analysis}

To compare antibody titres in diabetic patients with titres in nondiabetic subjects, matched control subjects were selected from the viral surveillance population. For every diabetic patient all possible controls were identified who matched the patient by sex and age (within 6 months), and who had blood drawn within 2 months of the patient. When more than one match was available, the control was selected by a random draw from the pool of matching subjects. This procedure yielded 33 matched pairs corresponding in sex, age, and time of blood drawing for antibody determinations.

To compare the antibody titres of diabetic patients and control subjects, the titres were divided into three groups: a 'zero titre' group in which no antibody was observed at a dilution of $1: 4$, a 'low 


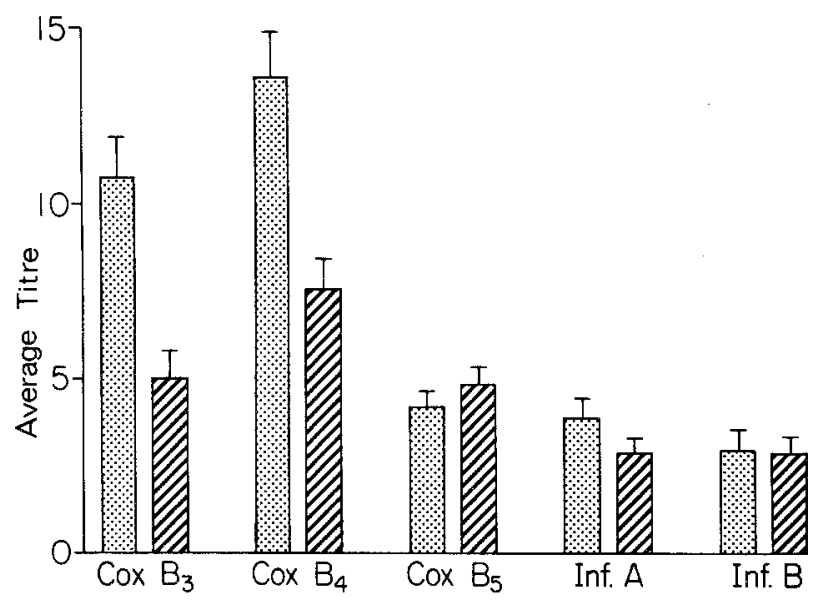

Fig. 1. Antibody titres (mean $\pm \mathrm{SEM}$ ) for Coxsackie $B 3, B 4, B 5$ $(n=33)$ and Influenza $A$ and $B(n=16)$ in Diabetic $Z \mathbb{Z} A$ and matched control subjects

titre' group in which the antibody titre was 4-32, and a 'high titre' group in which the titre was 64-256.

The data were analyzed using the standard method of logistic regression [8,9]. We tested the null hypothesis that the risk of being diabetic does not depend upon the particular class of antibody response ('zero', 'low' or 'high') to the viruses.

\section{Results}

Thirty-four non-diabetic individuals from the surveillance study had Coxsackie $B$ viruses isolated from their combined nose/throat swab cultures. All he culture-substantiated Coxsackie B4 infections occurred between December 1975 and December 1976, and all Coxsackie B 5 infections between November 1976 and October 1977. Coxsackie B 3 infections were largely coincident with the Coxsackie B 5 infections. Serology from the entire surveillance population confirmed the outbreak.

The diabetic patients demonstrated several characteristics typical of Type 1 diabetes. There was a predominance of males (22/33) and the average age at onset of diabetes was 11 years. Islet cell antibodies were detected in the sera of $69 \%$ of the patients, with titres ranging from $1: 2$ to $1: 32$. Thirty of the 33 diabetics were HLA typed and the prevalence of HLA B 8 and B18 was increased, although total numbers were small.

During the time Coxsackie B4 virus was isolated from the surveillance population (December 1975 to December 1976), only two of the newly diagnosed diabetic patients had Coxsackie B4 antibody titres $>32$, compared with eight diabetics whose disease presented later. This non-uniform distribution of diabetic patients with higher B 4 titres was highly signif-
Table 1. Coxsackie B 3 and B 4 antibody titres in newly diagnosed diabetic and control subjects

\begin{tabular}{lrllr}
\hline $\begin{array}{l}\text { B4 antibody } \\
\text { titre group }\end{array}$ & \multicolumn{2}{l}{$\begin{array}{l}\text { B3 antibody } \\
\text { titre group }\end{array}$} & & \\
\cline { 2 - 5 } & 'zero' & 'low' & 'high' & total \\
\hline 'zero' & $14 / 8$ & $1 / 5$ & $3 / 3$ & $18 / 16$ \\
'low' & $5 / 2$ & $2 / 1$ & $3 / 1$ & $10 / 4$ \\
'high' & $4 / 7$ & $1 / 1$ & $0 / 5$ & $5 / 13$ \\
total & $23 / 17$ & $4 / 7$ & $6 / 9$ & $33 / 33$ \\
\hline
\end{tabular}

Number of diabetic/control subjects with Coxsackie B3 and B4 antibody titres in respective groups ('zero', 'low', 'high'). See text for definition of groups

Table 2. Relationship of level of Coxsackie antibody titre to significantly increased risk of having Type 1 diabetes in 33 cases and their matched controls

\begin{tabular}{llll}
\hline $\begin{array}{l}\text { Variable entering } \\
\text { the equation }\end{array}$ & $\begin{array}{l}\mathrm{X}^{2} \\
\text { associated } \\
\text { with } \\
\text { variable }\end{array}$ & $\begin{array}{l}\text { Degrees } \\
\text { of } \\
\text { freedom }\end{array}$ & \\
\hline Coxsackie B4 & 11.94 & 2 & $<0.005$ \\
Coxsackie B3 & 7.57 & 2 & $0.01<\mathrm{p}<0.025$ \\
$\begin{array}{l}\text { Coxsackie B3 X } \\
\text { Coxsackie B4 }\end{array}$ & 14.93 & 4 & $<0.005$ \\
Coxsackie B5 & 4.80 & 2 & $0.05<\mathrm{p}<0.10$ \\
\hline
\end{tabular}

Analysis was by hierarchical logit regression with the variables entering the equation in the order shown

icant ( $p<0.005, \mathrm{Z}=-2.84$ ) when the first 15 months of the study were compared with the later 15 months. A similar number of diabetics presented in each time period: 18 and 15 cases respectively.

The average viral antibody titres in the control and diabetic subjects are shown in Figure 1. The two groups of subjects had similar titres to Coxsackie B5 and Influenza A and B (available for Influenza in 16 out of 33). Coxsackie B 3 and Coxsackie B 4 titres were lower in the diabetic patients. Table 1 shows the number of diabetic and non-diabetic subjects with 'zero', 'low' and 'high' antibody titres to Coxsackie B 3 and B 4 and the statistical analysis is summarized in Table 2. The most significant association or risk was with low titres to Coxsackie B 4, followed by low or zero titres to Coxsackie B 3 and then the interaction between Coxsackie B3 and B 4 (Table 2). No significant risk was associated with Coxsackie B 5. We also examined whether age, HLA type, date of onset of diabetes, or islet cell antibody titre might be related to the subset of diabetic patients with low antibody responses to Coxsackie B 3 and B4. No such association was found, nor was any geographical clustering of the diabetes observed. 


\section{Discussion}

A large number of observations in both animals and man suggest a viral aetiology for at least some cases of Type 1 diabetes [10]. We hypothesize that the differences in antibody titres between diabetic and control subjects may be due to an impaired immune response to Coxsackie B3 and B 4, but other mechanisms must also be considered. A non-specific immuno-suppressive effect of their acute diabetic episode is not a likely explanation since the diabetic patients had normal antibody levels to Coxsackie B 5 and Influenza $A$ and B; and serum specimens obtained 2, 4, and 8 weeks post-diagnosis did not show a rise in antibody titres when the patient's diabetes. was controlled (data not shown).

Besides an impairment in immune responsiveness, the other major explanation which must be considered for the differences between diabetic and control subjects is the possibility of different Coxsackie B 3 and/or B 4 infection rates in the two populations. As is true for all serological studies, it is impossible to prove that infection rates were equivalent in the two groups. Differences in geographical location might suggest differences in exposure and therefore infection rates. However, the outbreak of Coxsackie B3 and $\mathrm{B} 4$ was not confined to a small geographical area but was generalized for the community and consequently probably included the diabetic patients. Also, we know from the viral surveillance study that, even in families without isolation of Coxsackie B3 or B4 viruses from their nose and throat cultures, the prevalence of Coxsackie B3 and B4 infections during the time of our study was $21 \%$ and $25 \%$ respectively as demonstrated by a fourfold rise in antibody titre. In addition, since for Coxsackie B 4 the highest risk is associated with a 'low' titre rather than a 'zero' titre, it is clear that differences in infection rate per se cannot account for our observations. In fact, the infection rates for Coxsackie B 4 as indicated by presence of antibody were similar for diabetic and control subjects ( $45 \%$ and 52\% respectively, Table 2). Thus most of the evidence suggests that the Coxsackie infection rates were likely to have been similar in diabetic and control subjects.

The findings reported here suggest that an impaired immune response may be aetiologically important in Type 1 diabetes. The conflict between our data and the elevated or more prevalent Coxsackie B4 titres in newly diagnosed cases reported by Gamble et al. $[3,5]$ is more apparent than real. They, like us, noted that during the fall, when Coxsackie B4 was probably more prevalent, a larger percentage of newly-presenting diabetic patients were negative for B 4 antibody than at other times $[5$, personal communica- tion]. In both Gamble's study [5, personal communication] and a report by Andersen et al [11], there was a tendency for the younger patients to have a lower prevalence of Coxsackie B 4 titres than non-diabetic subjects. The newly diagnosed diabetics in our study, mean age 11 years, were more comparable to the younger than the older patients in each of these reports $[5,11]$. It is reasonable to treat our results with circumspection in view of the small numbers but taken together with the other reports the data are highly suggestive.

It is possible to speculate that individuals with an impaired humoral immune response to Coxsackie B3 and B 4 are at increased risk of developing diabetes when exposed to these viruses. They would therefore present with diabetes at times when these viruses are prevalent, but would exhibit low antibody titres compared with controls. This proposed mechanism can, however, be applicable only to a proportion of diabetic patients, since many diabetics have normal antibody responses to Coxsackie B3 and B 4 [3, 5, 12-14]. Since many different viruses could cause diabetes, similar studies performed during outbreaks of other viruses may reveal deficient immune response to these viruses. Possibly, the deficient antibody response results in a more severe viral infection with greater resultant pancreatic B cell involvement, destruction, and diabetes than occurs in individuals with normal immune responses. Proof of this hypothesis will require the demonstration of an impaired antibody response in diabetic patients known to be infected.

Acknowledgements. The authors are grateful to K. Hillman, C. Berryman, and $\mathrm{H}$. Nichols for their excellent technical assistance and to S. MacMillan for typing the manuscript. This investigation was supported in part by NIH grants AM 17047, AI 12269, CA 18029 , HL 17265, USPHS grant SEA 7808, and a grant from the Juvenile Diabetes Foundation. JPP is the recipient of a Clinical Investigator Award (1K08 AM 00535). CMA is the recipient of a Fellowship Award from the American Diabetes Association, Washington Affiliate, and an award from the Oxford Regional Health Authority.

\section{References}

1. Connolly JH, Thomson D (1977) Coxsackie B 2 virus infection and acute-onset diabetes in a child. Brit Med $\mathrm{J} 2: 1008$

2. Yoon JW, Austin M, Onodera T, Notkins AL (1979) Virus-induced diabetes mellitus. N Eng J Med 300: 1173-1179

3. Gamble DR, Kinsley ML, FitzGerald MG, Bolton R, Taylor KW (1969) Viral antibodies in diabetes mellitus. Brit Med J 3: $627-630$

4. Gamble DR, Taylor KW (1969) Seasonal incidence of diabetes mellitus. Brit Med J 3:631-633

5. Gamble DR, Taylor KW, Cumming H (1973) Coxsackie viruses and diabetes mellitus. Brit Med J 4:260-262 
6. Palmer JP, Cooney MK, Crossley JR, Hollander PH, Asplin CM (1981) Antibodies to viruses and to pancreatic islets in nondiabetics and insulin dependent diabetic patients. Diabetes Care 4: 525-528

7. NIH Lymphocyte Microcytotoxicity Technician (1979) In: NIAID Manual of Tissue Typing Techniques 1979-1980, U.S. Department of Health Education, and Welfare, Publ. No. 80-545, pp 39-41

8. Holford TR, White C, Kelsey JL (1978) Multivariate analysis for matched case-control studies. Am J of Epid 197:245-256

9. Breslow NE, Day NE, Halvorsen KT, Prentice RL, Sabai C (1978) Estimation of multiple relative risk function in matched case-control studies. Am J Epid 108:299-307

10. Craighead JE (1981) Viral diabetes mellitus in man and experimental animals. Am J Med 70: 127-134

11. Andersen OO, Christy M, Arnung K, Buschard K, Christau B, Kromann H, Nerup J, Platz P, Ryder LP, Svejgaard A, Thomsen M (1977) Viruses and diabetes. In: Bajaj IS (ed) Diabetes, Proceedings of the IX Congress of the International Diabetes Federation. Excerpta Medica, Amsterdam, pp 294-298
12. Huff JC, Hierholzer JC, Farris WA (1974) An 'outbreak' of juvenile diabetes mellitus : consideration of a viral etiology. Am J Epid 100: 277-287

13. Hierholzer JC, Farris WA (1974) Follow-up of children infected in a coxsackie-virus B-3 and B-4 outbreak: no evidence of diabetes mellitus. J Inf Dis 129:741-746

14. Dippe SE, Miller M, Bennett PH, Maynard JE, Berquist KR (1975) Lack of causal association between coxsackie B 4 virus infection and diabetes. Lancet 1:1314-1317

Received: 9 June 1981

and in revised form: 25 January 1982

Jerry P. Palmer, M. D.

Diabetes Research Center (ZB-34)

Seattle Public Health Hospital

Quarters 8

1131-14th Avenue South

Seattle, W 98144, USA 